\title{
The Symbolic Meaning of Greek Dancing in Diaspora
}

\author{
By Maria-Irini Avgoulas ${ }^{*} \&$ Rebecca Fanany ${ }^{\dagger}$
}

\begin{abstract}
Maintenance of cultural practices in diaspora communities is a significant element of heritage. Such practices may also contribute to health and well-being, especially if they offer an opportunity for physical activity and social interaction health and wellbeing. For the Greek community of Melbourne, Australia, the maintenance of their cultural heritage continues to be central to the experience of the community and is manifested in a number of ways, including in the form of Greek dancing which has become a popular leisure activity. This study investigates the role Greek dancing plays in cultural maintenance and heritage identity among people of Greek background in Melbourne as well as its potential contribution to health and wellbeing. The symbolic meaning of dances well as its potential to motivate participation in physical activity are discussed. These findings of this study suggest that there is an important cultural dimension of dancing as a health promoting activity. For the participants in this study, the heritage aspect of this activity was of the greatest importance, while the physical benefits remained secondary although desirable. Dancing was associated with the idea of being Greek and the happiness a Greek environment provided. This highlights the emotional benefits of an activity that is culturally consonant and that contributes to the physical and emotional aspects of wellbeing.
\end{abstract}

Keywords: Culture, cultural identity, Greek dancing and music, Greek diaspora, health, wellbeing

\section{Introduction and Background}

Melbourne, Australia is the home to a large and well established Greek diaspora that dates to 1827 . The community expanded rapidly from 1945-1982 as new migrants arrived and began to settle in Melbourne (for a detailed discussion see Damanakis et al. 2014, Danousi 2015 among others). The current economic problems in Greece have resulted in another wave of migration that is made up of young people with the same hopes and aspirations as the earlier migrants that Australia would indeed be the 'lucky country' and 'a second homeland' for people of Greek origin (for a detailed discussion see Avgoulas, 2013). From the beginning, cultural maintenance and a Greek lifestyle, adapted to the Australian context has been important, and the community continues to support a number of Greek-oriented institutions, including churches, schools, cultural and sporting groups, and community organizations. These institutions and the activities they sponsor reflect the importance placed on cultural maintenance by the original

\footnotetext{
*Associate Lecturer, La Trobe University, Australia.

${ }^{\dagger}$ Senior Lecturer, School of Health, Medical and Applied Sciences, Central Queensland University, Australia.
} 
immigrant generation and the continued significance of heritage and cultural identity to younger members of the community who were born in Australia. Heritage, in this context, refers to a specific historical and cultural experience shared by members of the community. The presence of new migrants reinforces the community's link to Greece, but these newcomers are not numerous enough to alter the patterns of the established diaspora community or to cause a change in the perception of shared heritage.

One element of the cultural activities of the diaspora community is traditional Greek dancing that is an increasingly popular pastime for some members of the community. A number of groups are in existence and give members a chance to perform at various occasions associated with Australia's multicultural context. Many of these groups are associated with a dance school or provide some form of lessons or training to those interested. In this way, Greek dancing in Melbourne parallels similar activities in other cultural communities, and dance is seen as one element of culture that is compatible with the mainstream, English culture of the nation (see Bennett and Carter, 2001, for discussion of this). The value of folk dancing for various population subgroups in Australian society has been established (see, for example, Connor 2000, Gardner et al. 2008), but little consideration has been given to the link between dance, heritage and cultural maintenance and well-being. Instead, the focus on existing work has largely been the contribution of dance to fitness and social interaction.

\section{Literature Review}

\section{Culture and Wellbeing}

The existence of a relationship between culture and well-being has been noted by a number of authors (see, for example Diener and Diener 1995, Diener et al. 1995, Ariiendell et al. 1997). In the case of diaspora communities such as the Greeks in Melbourne, acculturation to the local cultural context is an important aspect of well-being that relates to an individual's feeling of belonging to a cultural group (Phinney 1990). For this reason, a number of scholars view acculturation as having two dimensions, the maintenance of heritage culture and adaptation to the local context (see Berry 1997, Liebkind 2001). The Greek community of Melbourne has largely established what Phinney et al. (2001) refer to as a bicultural identity where individuals of Greek background identify strongly with their heritage culture but are also integrated into the cultural mainstream.

The literature suggests that this type of successful acculturation is most conducive to well-being (Berry 1997, Howard 1998, Phinney et al. 2001). At the same time, the maintenance of strong links to the heritage culture has been shown to enhance well-being and represents the most adaptive strategy in accommodating to a new culture (LaFramboise et al. 1993). For adolescents in particular, it has been suggested that an awareness of ethnic heritage is integral to the formation of a personal identity (Wakefield and Hudley 2007). These concepts of personal, collective and cultural identity have been suggested to be central to well-being 
(Usborne and Taylor 2010) with cultural identity being one of the most important factors in collective identity (Schwartz et al. 2008). For many younger members of the Melbourne Greek diaspora, participation in Greek dancing is a way of expressing their cultural identity and associating themselves with the larger community of people of Greek background in Australia, Greece and elsewhere in the world.

\section{Well-Being, Dance and Health}

Dance has long been viewed as being closely related to health (Ritter and Lowe 1996, Hanna 2006, Murcia et al. 2010), and the potential value of in addressing health and illness has received some attention (Hackney et al. 2007, Belardinelli et al. 2008). It has also been found that dance can support increased well-being (Murcia et al. 2010), although this relates to more to direct participation than to spectator attendance. In general, participation in the arts in general, and dance specifically, has been observed to be becoming less active, with fewer people participating directly than in the past (Bailey and Davidson 2005).

Despite this, the role physical activity can play in both health and well-being is increasingly accepted by scholars and researchers as well as by the general public. There is a large literature on the beneficial role of exercise in the management of chronic disease and also as a factor in quality of life (see Warburton et al. 2006, Haskell et al. 2007). Music is also strongly linked to emotional well-being (see Laucka 2006) and dance combines music with physical activity in the form of patterned motions and meaningful gestures. Music in a range of contexts has been shown to improve mood and encourage movement (Large 2000), while dance itself may facilitate social interaction occurring through participation in a group activity that requires coordinated activity and cooperation (McNeil 1995).

At present, work on individual motivation for participation in dance of any kind, including folk dance, remains limited. In a study conducted in Finland, Nieminen (1998) found that developing a social network, physical fitness, and a desire to perform were the main motivations for individuals to take part in dance classes and groups. Kreutz (2008), whose work concerns ballroom dancing, noted that was widely seen as a form of exercise, as providing an opportunity to socialize, and offering an emotional benefit. Murcia et al. (2010) also found that the physical benefits of dance to be the most significant aspect of the activity to many participants, alongside emotional well-being and personal satisfaction. They also found that their participants had multidimensional perceptions of the benefit of dance and that more female participants in their study reported more positive benefits than did the male participants. The present study contributes to this area of study and extends it to include the question of cultural identity and heritage in the context of well-being, specifically as understood by members of the Greek diaspora in Melbourne. 


\section{Methodology}

In depth semi - structured interviews were carried out with 19 individuals who were currently enrolled at a local Greek dance school in metropolitan Melbourne, Australia. Of the 19 participants, four were male and 15 were female. Their ages ranged from 18 to 58, with the majority (13 individuals) born in Australia. In addition, all participants had completed some form of formal education, some at the high school level, with the majority having completed or currently enrolled in a University degree. Interviews were held at the dance school with the consent of the management and conformed to the requirements of the Australian National Statement on Ethical Conduct in Human Research. Interviews were recorded digitally and later transcribed for analysis.

The interview texts were subsequently analysed thematically and a number of themes identified. These themes related to several experiential domains, including the participants motivation for participating in Greek dancing; the meaning of Greek dancing to them in terms of their cultural heritage; the connection between dancing and the participants' conceptualization of identity; and the participants interest in pursuing health and fitness through participation in Greek dancing.

\section{Findings and Discussion}

The participants in this study had a number of motivations for taking part in Greek dancing classes as well as the opportunities for performance as part of the dance school. Three specific motivations were relevant to the majority of participants. These were the connection to Greece and their heritage that dancing represented; a desire to engage in exercise and improve their fitness, including weight management; and an outlet for stress and source of relaxation. Some of the participants expressed these views as follows:

"Greek dancing is about developing your social relations with fellow Greeks, exposing yourself to your culture to your background, upbringing, holding traditions. Very fun, very dynamic, very active so you get a good workout out of it. It's both culture and very good form of exercise as well." [18 year old, Australian born male]

"Dancing is my culture and what defines me as a Greek - it's also a type of exercise - see the gym I don't like. It's not the same, it's the friendships as well, and, for me, friendships as very important and being part of something and learning, and it's exercise. Dancing works out so many muscles you feel it." [18 year old, Greek born male]

"Fitness and getting healthy and losing weight, and I can see these result, and the benefits and I feel better - the emotional side, I'm happy. There are the psychological benefits after a long day coming here I feel better emotionally, and this is something that I don't get when I go to the gym." 42 year old, 
Australian born female]

"Dancing is my sanity, my escape, my de-stress, my time - dancing is my time as a mum. If I'm upset, I go to dancing and I'm a new person. It's refreshing, it's a support - my time for me." [40 year old, Australian born female]

"That connection to Greece, and I love to learn. I feel that release." [29 year old, Greek born female]

For all of the participants, their identity as a member of the Greek community was of great importance as was maintaining their heritage in the Australian context. The majority of the participants was born in Australia and was fully integrated into the mainstream culture. Nonetheless, they had been exposed to certain aspects of Greek culture for their whole life through parents or grandparents who were part of the early immigrant community. In this, the approval of these older relatives was an important consideration as was ensuring that the cultural heritage they inherited continued into the next generation through their own children. A sample of their comments includes:

"Being part of something Greek and learning about it is very important to me. It's like I get a tick from my grandparents, a tick from my parents and one for myself." [18 year old, Australian born male]

"My Greek culture and heritage brought me here, and I looked it up and found it, and it's afterhours so it's great for the older ones. I really look forward to dancing classes. It's my highlight of the week and mentally is good for me." [51 year old, Australian born male]

"Being Greek and dancing just makes you feel good, happy and healthy. I can't explain it. It's just very important to me." [29 year old, Greek born female]

"I don't want to lose our culture. . . the maintenance of our culture. It's important and our responsibility, and for them [children] to keep and maintain and hand down to their kids." [40 year old, Australian born female]

Each of the participants in this study felt a strong Greek identity, alongside their feelings of being Australian. For the participants who recently emigrated to Australia, their Greekness represented the main component of their individual and group identity. The Australian born participants, however, were generally fully integrated in Australian society, were primarily English speakers, and shared many of the attitudes and activities that represent Australian norms. For them, being Greek tended to be relevant in a limited range of social context, mostly focusing on the home and family. Their participation in Greek dancing fit into their selfconception of Greek identity and served to link them to the Greek community in Australia and elsewhere and also to distinguish them from other Australians. All of 
the participants were concerned about potentially losing this Greek identity and saw their participation in Greek dancing as a way of reducing that risk. Some of the participants commented:

"Dancing helps a lot it [Greek identity], reinforces it on a daily basis. You don't think, 'how can I keep my Greekness?' But coming here, it's a routine and it reinforces it, and, as a migrant, the reminder that I'm Greek and doing something Greek is very important." [18 year old, Greek born female]

"My ylarló comes to grandparents' day. She feels very proud and [says,] 'my grandchildren are keeping my Greek culture, ethnicity alive - $\mu \pi \rho \alpha ́ \beta o$

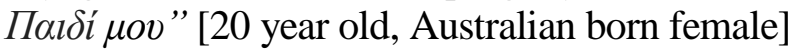

"It's a very emotional experience for family. Like my ylapló would cry in the crowd when she would see me perform - as it would remind her of my $\pi \alpha \pi \pi \circ v$ and even Greece. It's of great emotional benefit for her." [23 year old, Australian born female]

"I've told my friends in Greece that I do Greek dancing here, and they said it's great and they were happy that I'm doing something Greek here. See, in Greece, they do make fun of you when you dance Greek. It's because they don't have to do it there. Even if they don't do it, they are Greek and they won't lose it. They live in Greece. It's like any celebration, if they miss a celebration like Christmas, it will come again, but, here, we can lose it, and I don't want to lose it. See I have lost it in a way, as I have left Greece and I'm trying to keep it here. Hold onto it. It's like they say, you never know what you have until you lose it. But here, it's effort, and we have to do it. So, my friends from Greece are happy and say 'bravo' that I'm keeping the Greek here.” [19 year old, Greek born female]

Separate from the role Greek dancing might play in maintaining physical fitness and providing exercise, a number of participants made an explicit connection between the activity and well-being, both for themselves as well as generally. In particular, several participants noted the contribution their performances make to the well-being of the older members of the community and also positive impact on their own mood and mental state. Some of their comments included:

"When older people see us dance, it is so good for their health as they see us carrying the traditions. Their psychological health - older people want to see our performances and even cry, and they don't even know us." [23 year old, Australian born female]

"At many performances, we grab older people and dance with them, and they like it, and it reminds them of being in Greece" [ 23 year old, Australian born female] 
"And for my health, it's great. You feel fit and health, and that you have done something good for yourself. And there is the socializing. Everyone is Greek here. You feel you have done a good workout but, at the same time, you learn something." [40 year old, Australian born female]

"It's great for the mind, the connection to my culture, and heritage - and there is the physical too, and, with other forms of exercise, I only get the physical. I haven't experienced the emotional benefits I get here." [56 year old, Australian born male]

The participants in this study all placed great importance on their Greek heritage and were anxious, not just to maintain it, but to demonstrate it. In other words, they wished to be acknowledged as members of the Greek community and part of the diaspora in Australia. While Australian multicultural policy encourages citizens to participate in activities related to their cultural heritage and provides for the teaching and maintenance of languages other than English that are spoken in the community, it has not always been the case that members of distinct diaspora groups felt able to demonstrate this aspect of their identity openly (see, for example, Tsolidis and Pollard 2009). Over time, however, it has become more acceptable to display a non-English cultural identity in Australia, and the participants in this study, like many members of the Greek community in Melbourne, are proud of their heritage and wish to be seen as "Greek" at least in the Australian context.

The concept of Greek identity in Australia has a number of components that derive from the experience and actions of the migrant generation whose members now constitute the oldest part of the diaspora community. This concept of Greekness has in the past centered on use of the Greek language, religious affiliation with the Orthodox Church, and certain customs and activities associated with Greek heritage culture but adapted to the Australian context. The Greek dancing classes that are the context of this study are an example of this. While traditional dancing may not be of great importance to individuals of a similar age and background to the participants in this study, as noted by one of them above, it is an integral part of community life in Melbourne, in part because dance and other traditional art forms are accommodated in various forums under multicultural policy (see Lee al. 2012) but also because such activities are consonant with the participants' sense of self as well as their Australian identity.

One of the most interesting aspects of the participants' motivation to take part in Greek dancing was a desire for exercise as an adjunct to physical fitness. The focus on these issues, including weight management, is very strong in Australia, and it is perhaps not surprising that many of the participants specifically mentioned the role Greek dancing plays as a form of exercise and fitness strategy. It is also likely that a part of the popularity of this activity can be attributed to this exercise function which is consistent with an important aspect of Australian mainstream culture as well as the cultural component identified with being Greek. In fact, it is unclear to what extent Greek dancing might seem attractive to many of the participants if it were less closely aligned with the concept of socially desirable 
fitness activity that dominates Australian society. In fact, many participants regard their dancing as a replacement for other kinds of physical activity, such as going to the gym, and hence see themselves as fulfilling two important demands: the need to maintain health and be physically fit and the desire to demonstrate their Greekness by taking part in a "Greek" activity.

The adaptation of traditional dance to the Australian context, where it fits into the category of folk dance that is seen as part of the experience of the various cultural communities that make up the broader Australian community, is notable. The younger members of the Melbourne Greek community are generally highly integrated into the Australian context and increasingly espouse Australian values and social behavior. This integration has been facilitated by language, with the majority of the community, except for the oldest members, being speakers of English (Tamis 2010). The movement of people of Greek background into the English-speaking mainstream in Australia has also been significant in the adaptation of the Greek way of life to more conform to the Australian norm. In this sense, the elements of behavior and experience that are seen as constituting Greek cultural identity have emerged from the Australian context and the norms of the English-speaking society. This process began decades ago when the institutions of the Greek diaspora community began to develop and has continued to the present time. This also accounts for the widely observed phenomenon where members of diaspora communities experience culture shock upon visiting Greece, much less attempting to return there to live (see, for example, Christou 2009). It is not unusual for them to find that the elements that constitute being Greek in the location where they were living are quite different from those seen as central by Greeks living in Greece (see, for example, Holeva 2004). This can be seen as the result of language shift, the influence of the mainstream culture, and the fact that the structure of the diaspora institutions has come largely from the first generation of migrants, whose views and perceptions reflect the Greece of their youth rather than the modern context of today.

Interestingly, it has been observed that diaspora communities such as the one in Melbourne are increasingly connected both to Greece and to other Greek communities elsewhere in the world through individual-level activity on the internet and in social media. The advent of rapid, inexpensive digital communication technologies has allowed for a level of interaction between people who are widely separated by distance and also for an unprecedented flow of information. The significance of this in Greek diaspora communities has been noted and has been observed to be an important means by which younger individuals are coming to understand their heritage background (see Panagakos 2010). The importance of a presence on social media in the context of cultural identity was observed among the participants in this study who hoped that their performances as part of the dance school would receive attention on YouTube and generate favorable comments from viewers. In this, social media seems to have become a new forum for the creation and maintenance of a specific ethnic heritage which, for the participants in this study, was associated with a sense of personal pride and also belonging to the larger Greek community in Melbourne, Australia and worldwide. 
For the participants in this study, their participation in Greek dancing was a clear link to their heritage, as they understood it, and also strengthened the bond between the generations of the diaspora. All of the participants understood that it was members of the immigrant generation who had struggled to establish the community and recreate certain aspects of Greek life in Melbourne. They generally respected this effort and genuinely wished to please parents and grandparents by participating in the institutions of the community. Many of them were surprised at the extent to which their participation in Greek dance pleased these older members of the community, and this was an added inducement to continue. In this, it is important to note that Greek dancing itself, as a cultural activity, derives from this older generation's perceptions of their culture of origin and its characteristic elements (see Thomas 2003, for discussion of this). The participants in this study tended to seek the approval of family members, and the Greek community in general, for their dancing, which suggests the social value of the activity alongside the personal satisfaction they derived from participation.

Overall, the participants made a strong link between their dancing and their overall well-being that was observed to have a number of separate dimensions. One important aspect of this was the perception that dancing allowed them to express the Greek side of their individual identity and maintain a strong connection to the Greek community. The contribution of a strong cultural identity to well-being has been established by a number of authors (Phinney et al. 2001, Ryff et al. 2003, Umana-Taylor 2004, among others) and is apparent in the participants in this study. A second aspect of the participants' well-being derives from their perception that their Greek dancing provides a significant level of exercise and contributes to their overall health and fitness. This link is wellestablished and is supported by a growing body of literature (see Penedo and Dahn 2005). Participation in a regular form of physical activity also has high social value in Australia and is widely viewed as the individual taking care of him or herself. This view was visible in the statements of participants and reflects a generalized view I Australian society. An additional aspect of well-being deriving from participation in Greek dancing is the opportunity to socialize and separate oneself from problems and concerns that derive from other domains of life. This role of their participation in dance was stressed by several individuals who viewed the activity as an escape from other problems, a way of relieving stress and an opportunity to clear their mind. Leisure activities are known to contribute to wellbeing and to be important elements of happiness (Newman et al. 2014).

Taken together, there are at least three different aspects of Greek dancing that were seen by participants in this study as having a direct contribution to their wellbeing and, by extension, to their general health. This gave them a strong sense of happiness that came from fulfilling a number of psychological demands relating to their conceptualization of personal identity as Greek and Australian, to their desire to please older relatives and maintain their Greek heritage, to participate in a physical activity that provided exercise and contributed to fitness, and to engage in a leisure pursuit that served as an opportunity to relieve stress and shift their focus away from their problems. The ability of Greek dancing to offer these psychological and social benefits is reflected in its popularity in the Melbourne 
Greek community and its attraction to younger individuals who are highly integrated into the Australian mainstream.

\section{Conclusion}

The results of this study suggest the importance and potential value of leisure activities that are consonant with the heritage identity of individuals as well as with the values of the larger social context in which they live. This is especially relevant in multicultural nations like Australia where there may be a significant mismatch of values, attitudes and social norms between the English-speaking mainstream and the practices of various cultural communities. While the potential for conflict exists and has been noted for some ethnic groups (see, for example, Renzaho et al. 2011, Milner and Khawaja 2012; among others), the Greek diaspora has been successful in bridging this gap and acculturating successfully into the Australian context. Nonetheless, the findings of this study suggest that heritage and cultural identity remain important, even to individuals who have shifted considerably from the patterns of behavior and action established by the immigrant generation.

There can be no doubt that current circumstances also contribute to the social and psychological benefit attributable to Greek dancing among the participants of this study. The role of social media and the digital environment should not be overlooked in seeking to understand the ways in which younger members of the Greek community in Melbourne and Australia see themselves and choose to display their "Greekness". It is likely that this same technology has contributed to a more desirable view of heritage culture in general and the fact of dual identity that characterizes the experience of many Australians. By being able to establish and maintain personal connections with others of similar background as well as with friends and family in Greece, it is clear that the participants in this study, as well as others like them in the Melbourne community, have been able to reshape their self-conception and develop a new Greek identity of which folk dancing is a part.

The prime importance placed on maintenance of cultural heritage as well as the community institutions established by the immigrant generation to Melbourne is recognized by individuals of all ages in the Greek diaspora community. The contribution of dancing groups to this is significant and suggests that this activity will continue to be seen as valuable, especially as its other social benefits are consonant with the perceptions of the Australian community in general. Even as the nature of being Greek in Australia continues to change over time with the experience of community members, it appears that dancing, as a manifestation of heritage culture, is likely to have a play in the culture-specific activities of the group. In this, it is interesting to note that the presence of new Greek immigrants, whose number remains small, has not had the potential to change the nature of the local perception of Greekness. Instead, these newcomers have been observed to be accommodating to the norms of the local community. This suggests that the conceptualization of Greekness built on the perceptions and memories of the 
immigrant generation is strong and benefits from its compatibility with the Australian mainstream in which it developed. The findings of this study indicate that future studies of other dancing groups of communities in diaspora would be useful in further understanding issues of the symbolic aspects of cultural identity, as would similar study in Greece that would provide a comparison of the participant experiences described here.

Overall, it can be concluded that Greek dancing, as one manifestation of a Greek identity among members of the Melbourne diaspora community, has important social and psychological benefits for those who take part in it as well as for the overall well-being of the community in addition to the individuals themselves. These benefits may be recognized explicitly or manifested in an implicit manner but suggest the high social value of the activity within the diaspora community and are a manifestation of the expression of heritage culture and a uniquely local understanding of Greekness within the larger Australian context.

\section{References}

Arrindell WA, Hatzichristou C, Wensink J, Rosenberg E, van Twillert B, Stedema J, Meijer D (1997) Dimensions of national culture as predictors of cross-national differences in subjective well-being. Personality and Individual Differences 23: 3753.

Avgoulas M (2013) The Greek diaspora of Melbourne, Australia. Polidromo - Periodical for Bilingualism and Multiculturalism in Education and Society 6(1): 54-58.

Bailey BA, Davidson JW (2005) Effects of group singing and performance for marginalized and middle-class singers. Psychology of Music 33: 269- 303.

Belardinelli R, Lacalaprice F, Ventrella C, Volpe L, Faccenda E (2008) Waltz dancing in patients with chronic heart failure. New form of exercise training. Circulation Heart Failure 1: 107-114.

Bennett T, Carter D (2001) Culture in Australia: Publics, Policies, Programs. Cambridge, UK: Cambridge University Press.

Berry J (1997) Immigration, Acculturation and Adaptation. Applied Psychology: An International Review 46: 5-68.

Christou A (2009) Emulating the Homeland - Engendering the Nation: Agency, Belonging, Gender and Identity in Second-Generation Greek-American Migrant Stories. In D Conway and RB Potter (eds), Return Migration of the Next Generations: $21^{s t}$ Century Transnational Mobility, 101-118. Ashgate, Surrey, UK and Burlington, VT.

Connor M (2000) Recreational Folk Dance: A Multicultural Exercise Component in Healthy Ageing. Australian Occupational Therapy Journal 47(2): 69-76.

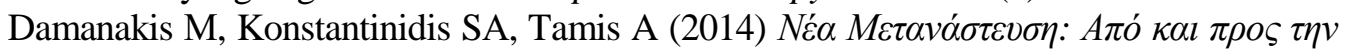

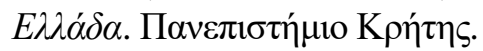

Danousi J (2015) Memory and Migration in the Shadow of War: Australia's Greek Immigrants after Word War II and the Greek Civil War. Cambridge, UK: Cambridge University Press.

Diener E, Diener M (1995) Cross-cultural correlates of life satisfaction and self-esteem. Journal of Personality and Social Psychology 6: 653-663.

Diener E, Diener M, Diener C (1995) Factors predicting the subjective well being of 

nations. Journal of Personality and Social Psychology 69: 851-864.

Gardner SM, Komensaroff P, Fensham R (2008) Dancing beyond Exercise: Young People's Experience in Dance Classes. Journal of Youth Studies 11(6): 701-709.

Hackney ME, Kantorovich S, Earhart G (2007) A study on the effects of Argentine tango as a form of partnered dance for those with Parkinson disease and the healthy elderly. American Journal of Dance Therapy 29: 109- 127.

Hanna JL (2006) Dancing for health. Conquering and preventing stress. Lanham, MD: AltaMira Press.

Haskell W, Lee IM, Pate RR, Powell E, Blair S, Franklin B, et al. (2007) Physical activity and public health. Updated recommendation for adults from the American College of Sports Medicine and the American Heart Association. Circulation, 116, 1 - 13. Ho, R.T.H.

Holeva A (2004) Current Trends of the Cultural and linguistic Values of the Greek Australian Community in South Australia. International Education Journal 4(4): 212-225.

Howard R (1998) Being Canadian: Citizenship in Canada. Citizenship Studies 2: 133-152.

Kreutz G (2008) Does partnered dance promote health? The case of tango argentino. The Journal of the Royal Society for the Promotion of Health 128: 79 - 84.

Large EW (2000) On synchronizing movements to music. Human Movement Science 19: $527-566$.

Laukka P (2006) Uses of music and psychological well-being among the elderly. Journal of Happiness Studies 8: 215-241.

LaFramboise T, Coleman H, Gerton, J (1993) Psychological Impact of Biculturalism: Evidence and Theory. Psychological Bulletin 114: 395-412.

Lee IS, Arcodia C, Lee, TJ (2012) Key Characteristics of Multicultural Festivals: A Critical Review of the Literature. Even Management 16(1): 93-101.

Liebkind K (2001) Acculturation. In R Brown, S Gaertner (eds) Blackwell Handbook of Social Psychology: Intergroup Processes, 386-406. Oxford, UK: Blackwell.

McNeill WH (1995) Keeping together in time: Dance and drill in human history. Cambridge, MA: Harvard University Press.

Milner K, Khawaja NG (2012) Sudanese Refugees in Australia: The Impact of Acculturation Stress. Journal of Pacific Rim Psychology 4(1): 19-29.

Murcia CQ, Kreutz G, Clift S, Bongard S (2010) Shall we dance? An exploration of the perceived benefits of dancing on well-being. Arts \& Health 2(2): 149-163

Newman DB, Tay L, Diener E (2014) Leisure and Subjective Well-Being: A Model of Psychological Mechanisms as mediating Factors. Journal of Happiness Studies 15(3): 555-578.

Nieminen P (1998) Motives for dancing among Finnish folk dancers, competitive ballroom dancers, ballet dancers and modern dancers. European Journal of Physical Education 3: 22 - 34.

Panagakos A (2010) Downloading New Identities: Ethnicity, Technology and Media in the Global Greek Village. Global Studies in Culture and Power 10(2): 201-219.

Penedo FJ, Dahn JR (2005) Exercise and Well-Being: A Review of Mental and Physical Health Benefits Associated with Physical Activity. Current Opinion in Psychiatry 18(2):189-193.

Phinney J (1990) Ethnic Identity in Adolescents and Adults: A Review of Research. Psychological Bulletin 108: 499-518.

Phinney JS, Horenczyk G, LIebkind K, Vedder P (2001) Ethnic Identity, Immigration and Well-Being: An Interactional Perspective. Journal of Social Issues 57(3): 493-510.

Renzaho AMN, McCabe M, Sainsbury WJ (2011) Parenting, Role Reversals and the 
Preservation of Cultural Values among Arabic Speaking Migrant Families in Melbourne. International Journal of Intercultural Relations 35(4): 416-424.

Ritter M, Low KG (1996) Effects of dance/movement therapy: A meta-analysis. The Arts in Psychotherapy 23: 249-260.

Ryff CD, Keyes CLM, Hughes DL (2003) Status inequalities, perceived discrimination, and eudaimonic well-being: Do the challenges of minority life hone purpose and growth? Journal of Health and Social Behavior 44: 275 -290.

Schwartz SJ, Zamboanga BL, Weisskirch RS (2008) Broadening the study of the self: Integrating the study of personal identity and cultural identity. Social and Personality Compass 2: 635-651.

Tamis AM (2010) Greek language and culture in Australia. In AM Tamis, CJ Mackie, S Byrne (eds) Philathenaios, studies in honour of Michael J. Osborne. Athens, Greece: Greek Epigraphic Society.

Thomas T (2003) Older Migrants and their Families in Australia. Family Matters 66:4045.

Tsolidis G, Pollard V (2009) Being a "Wog" in Melbourne: Young People's SelfFashioning through Discourses of Racism. Discourse: Studies in the Cultural Politics of Education 30(4): 427-442.

Umana-Taylor AJ (2004) Ethnic Identity and Self-Esteem: Examining the Role of Social Context. Journal of Adolescence 27:139-146.

Usborne E, Taylor DM (2010) The Role of Cultural Identity Clarity for Self-Concept Clarity, Self-Esteem and Subjective Well-Being. Personality and Social Psychology Bulletin 36(7): 883-897.

Wakefield WD, Hudley C (2007) Ethnic and Racial Identity and Adolescent Well-Being. Theory into Practice 46(2): 147-154.

Warburton DE, Nicol CW, Bredin S (2006) Health benefits of physical activity: The evidence. Canadian Medical Association Journal 174: 801-809 
